\title{
Cromófobo Renal Gigante
}

\section{Giant Renal Chromophobe Carcinoma}

Pedro Bargão Santos ${ }^{1,2}$, Fernando Ferrito², João Almeida Dores ${ }^{1}$, Ana Maria Afonso ${ }^{3}$

Autor Correspondente:

Pedro Bargão Santos [pbargao@gmail.com] Rua Mário Botas, 1998-018 Lisboa, Portugal

\section{RESUMO}

O carcinoma de células renais cromófobo é uma entidade histológica rara de carcinoma de células renais. Descreve-se um caso invulgar, de apresentação clínica invulgar, num homem de 50 anos, assintomático. Trata-se de uma massa renal de grandes dimensões $(224 \times 180$ mm) à direita, sem lesões secundárias associadas. O doente não apresentava sintomas, como dor lombar ou abdominal, ou hematúria, referindo apenas discreto aumento do volume abdominal. O achado foi ecográfico em exames de rotina. $O$ diagnóstico de presunção em imagem de tomografia computorizada foi de tumor renal primário. Realizou-se nefrectomia radical que decorreu sem intercorrências assim como o pós-operatório. O resultado histológico foi de carcinoma de células renais, variante cromófoba. Apesar das dimensões da lesão, existem casos, incluindo o atual, que têm evolução favorável e onde a indicação para a nefrectomia radical é o tratamento de eleição.

PALAVRAS-CHAVE: Carcinoma Células Renais; Nefrectomia; Neoplasias Renais

\section{ABSTRACT}

Chromophobe renal cell carcinoma is a rare histological entity of renal cell carcinoma. An unusual clinical case presentation is described in a 50-year-old man, asymptomatic - a giant right renal mass $(224 \times 180 \mathrm{~mm})$ with no associated secondary lesions. The patient had no symptoms, such as low back or abdominal pain or even hematuria. His unique complain was a slight increase in the abdominal volume. This finding was done by ultrasonography on routine exams. The presumptive computed tomography diagnosis was primary renal tumor. A right radical nephrectomy was made without perioperative complications. The histological finding was a chromophobe variant of renal cell carcinoma. Despite the dimensions of the lesion, there are cases including the current one, which have a favorable evolution and where the indication for radical nephrectomy is the first option.

KEYWORDS: Carcinoma, Renal Cell; Nephrectomy; Kidney Neoplasms

1. Departamento de Urologia, CUF Descobertas Hospital, Lisboa, Portugal. 2. Departamento de Urologia, CUF Infante Santo Hospital, Lisboa, Portugal. 3. Departamento de Anatomia Patológica, CUF Descobertas Hospital, Lisboa, Portugal.

Recebido: 02/05/2017 - Aceite: 07/09/2017 


\section{INTRODUÇÃO}

O carcinoma de células renais (CCR) é o tipo mais comum de malignidade renal. Devido ao curso muitas vezes indolente deste tumor, os doentes podem apresentar doença avançada mesmo que assintomáticos. A deteção precoce e a avaliação do CCR ainda são difíceis, especialmente quando sintomas como hematúria e outras queixas genito-urinárias estão ausentes $\mathrm{A}$ tríade clássica de apresentação de massa palpável, hematúria e dor lombar ocorre em menos de $11 \%$ dos casos. ${ }^{1}$ Atualmente, cerca de $60 \%$ de todos os tumores renais são diagnosticados incidentalmente ${ }^{2}$ e cerca de $20 \%$ a 30\% apresentam doença metastática. ${ }^{3}$

Recentemente registaram-se avanços significativos na produção de novos agentes e abordagens para o tratamento do CCR avançado. ${ }^{3}$ No entanto, o tumor do rim continua a ser uma patologia cujo tratamento é essencialmente cirúrgico. A taxa de sobrevivência aos cinco anos de doentes não operados é de aproximadamente $10 \%,{ }^{4}$ o que representa um aumento de 2,5 vezes na mortalidade geral e específica tumoral em comparação com doentes operados. ${ }^{5}$

O carcinoma de células renais cromófobo (CCRC) é uma entidade histológica rara de carcinoma de células renais (CCR). ${ }^{6-8}$ Representa cerca de $5 \%$ destes casos de tumor e forma-se nas células que revestem os túbulos coletores. Este subtipo raro de carcinoma pode surgir em famílias como parte de uma doença genética rara chamada síndrome de Birt-Hogg-Dubé. A natureza genética da doença permitiu aos pesquisadores uma pequena janela de oportunidade para estudá-la. No entanto, muito pouco se sabe sobre a base genética do CCRC esporádico (não hereditário). O Cancer Genome Atlas (TCGA) encontra-se a estudar os casos esporádicos deste tipo de carcinoma renal. Embora raro, este subtipo é uma doença grave, e a única opção de tratamento é a cirurgia.

Relatamos o caso de um CCRC gigante (peso do tumor: $2640 \mathrm{~g}$ ) removido cirurgicamente em bloco. O tamanho do maior CCRC descrito é de $350 \times 180 \times 190$ mm de diâmetro, pesando 11500 g.7 O maior tumor do rim, ou envolvendo o rim (incluindo CCR, sarcoma, oncocitoma, angiomiolipoma, e nefroma quístico), foi um sarcoma perirrenal (tamanho tumoral: $400 \times 340 \times 130$ mm e peso: $8500 \mathrm{~g}) .,{ }^{9,10}$

\section{CASO CLÍNICO}

Homem de 50 anos de idade, aparentemente saudável, assintomático e sem medicação habitual regular. Consultor de sistemas de informação de profissão. Como ante- cedentes cirúrgicos referiu uma cirurgia otorrinolaringológica aos 22 anos ao septo nasal. O motivo da consulta de Urologia deveu-se a um achado imagiológico ecográfico acidental de uma massa renal à direita de grandes dimensões. Referia notar um aumento do volume abdominal desde há muitos anos (sic) que não valorizava. Negou alguma vez ter tido hematúria. Negou igualmente hipertensão arterial, tabagismo e obesidade. A inspeção evidenciava uma tumefação abdominal na região dos quadrantes abdominais superior, inferior e flanco à direita, região epigástrica e zona umbilical (Fig. 1). A massa palpável nos respetivos quadrantes, apresentava consistência dura, contornos aparentemente bem definidos, pouco móvel, de grandes dimensões (bola de andebol) mas sem despertar dor à palpação. Cronograma:

1. Aumento do volume abdominal desde há muitos anos (sic).

2. Março de 2015 - Achado imagiológico ecográfico acidental, em exames de rotina, de uma massa renal à direita de grandes dimensões.

3. 31 de março de 2015 - Realização de tomografia computorizada (TC) abdominal e pélvica para melhor caracterização da lesão (Fig.s 2 e 3).

4. 15 de abril de 2015 - Nefrectomia radical à direita via abdominal anterior - incisão de Chevron (Fig.s 4, 5 e 6).

5. 24 de junho de 2017 - TC torácica, abdominal e pélvica de seguimento, sem evidência de recidiva da doença.

O procedimento cirúrgico foi realizado através de uma abordagem abdominal anterior - incisão de Chevron (Fig. 4). O cólon ascendente foi rebatido e o tumor dissecado anterior e posteriormente, preservando a cápsula e a abundante neovascularização, evitando a hemorragia. O rim e os vasos do hilo renal foram identificados, procedendo-se ao seu isolamento e respetiva tripla laqueação (Fig. 5). O tumor foi removido cirurgicamente em bloco com o rim (Fig. 6). A peça anatómica media $220 \times 195$ x 80 mm e pesava $2640 \mathrm{~g}$ (Fig. 7). A cirurgia demorou cerca de 120 minutos e a perda de sangue foi 150 cc. Histopatologicamente, o caso foi diagnosticado como CRCC pT2bNx. O pós-operatório decorreu sem complicações. Não houve recorrência da doença aos três meses após a cirurgia e não houve necessidade de qualquer tipo de terapêutica adjuvante.

A peça de nefrectomia radical à direita, incluía gordura perirrenal e pesava 2640 g. O rim com $220 \times 195 \times 80$ mm, facilmente descapsulável. Superfície de secção quase totalmente ocupada por um tumor com 190 x 180 x $80 \mathrm{~mm}$, com aspeto variegado, parcialmente quístico, com áreas compactas amarelas, áreas hemorrágicas e 


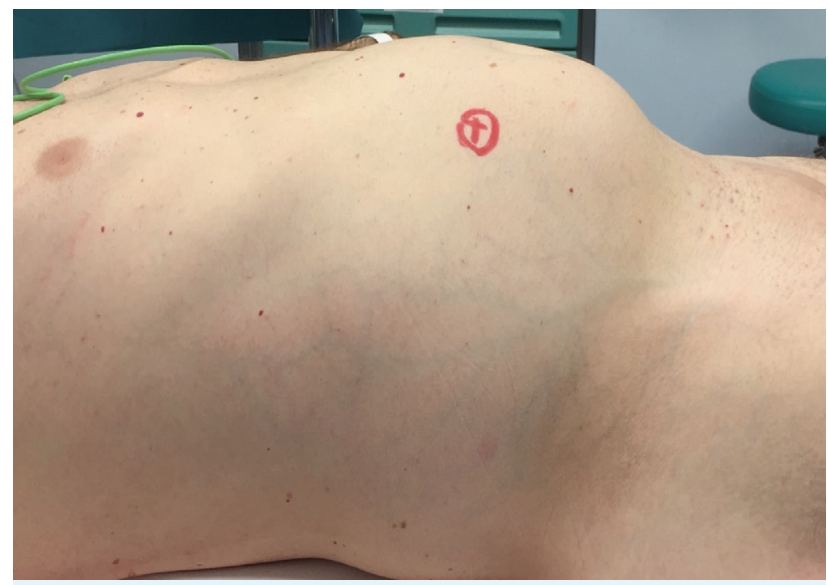

FIGURA 1. Efeito da massa no volume abdominal.

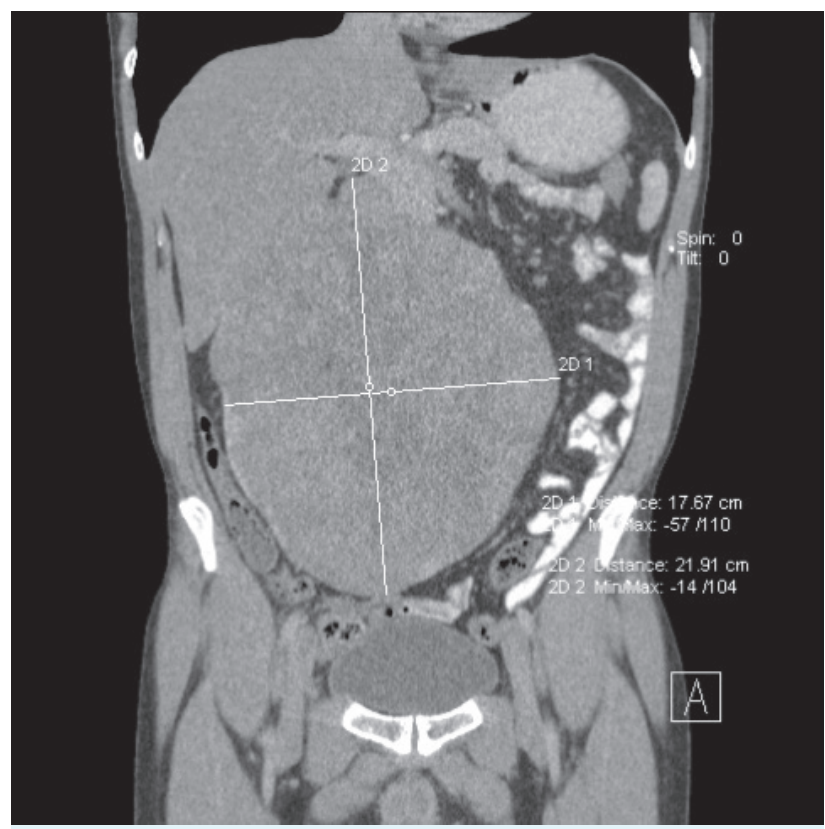

FIGURA 2. Imagem da TC pré-operatória - corte coronal.

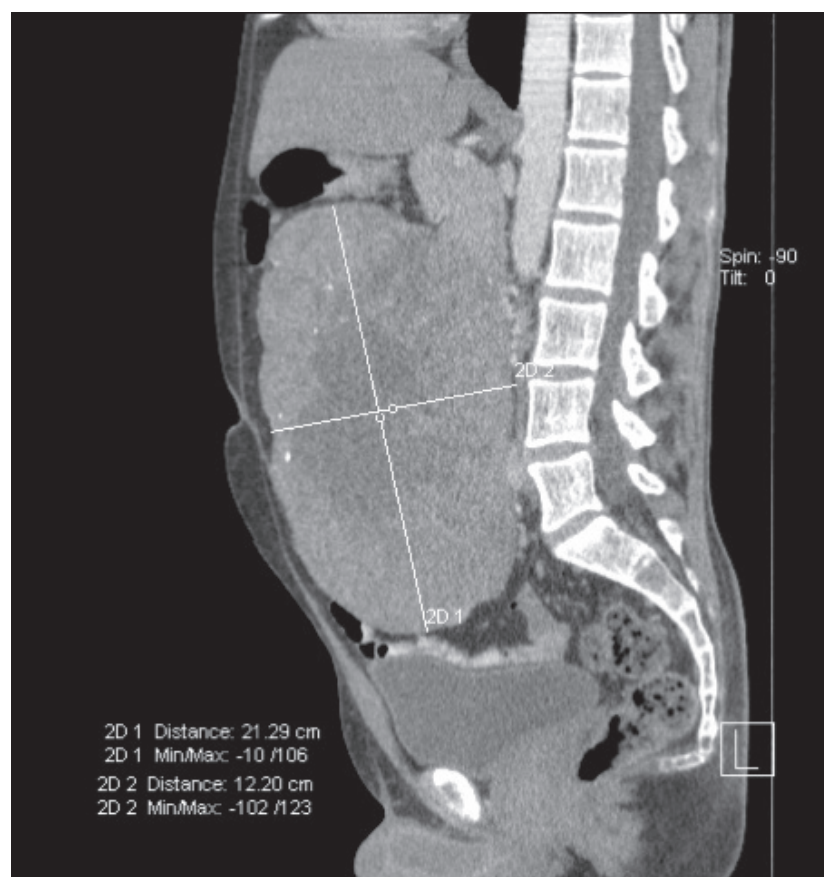

FIGURA 3. Imagem da TC pré-operatória - corte sagital.

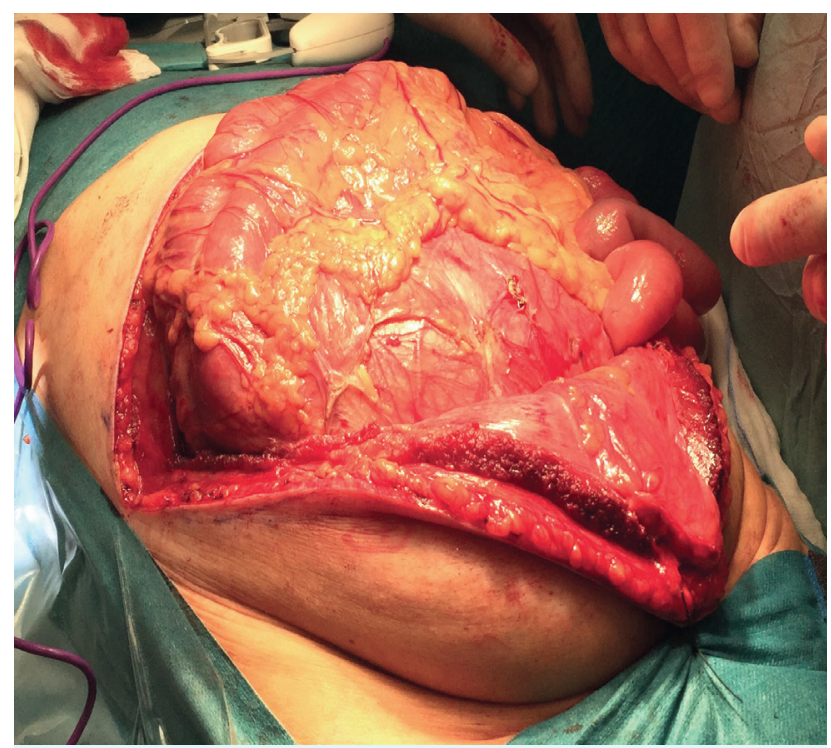

FIGURA 4. Incisão abdominal de Chevron possibilitando excelente exposição anatómica.

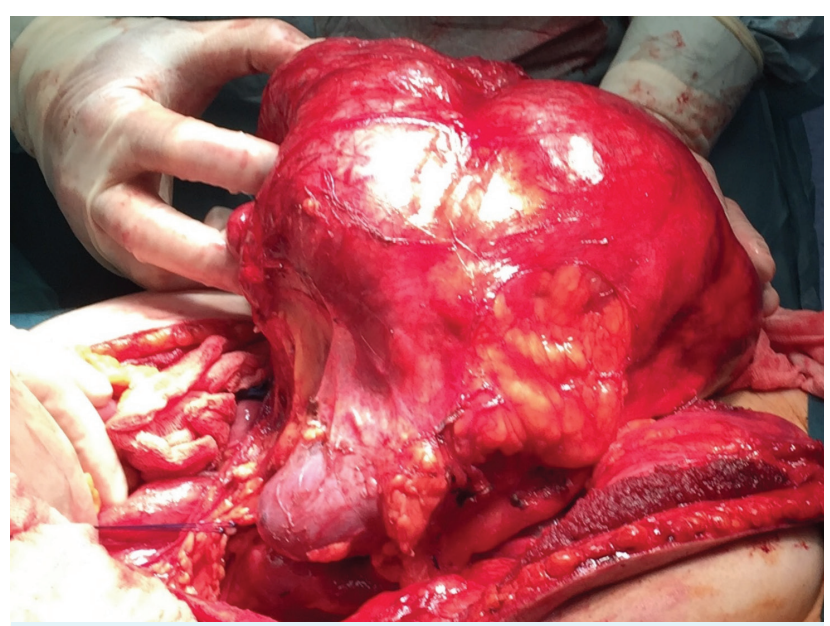

FIGURA 5. Pormenor de passo cirúrgico anterior à remoção da peça operatória.

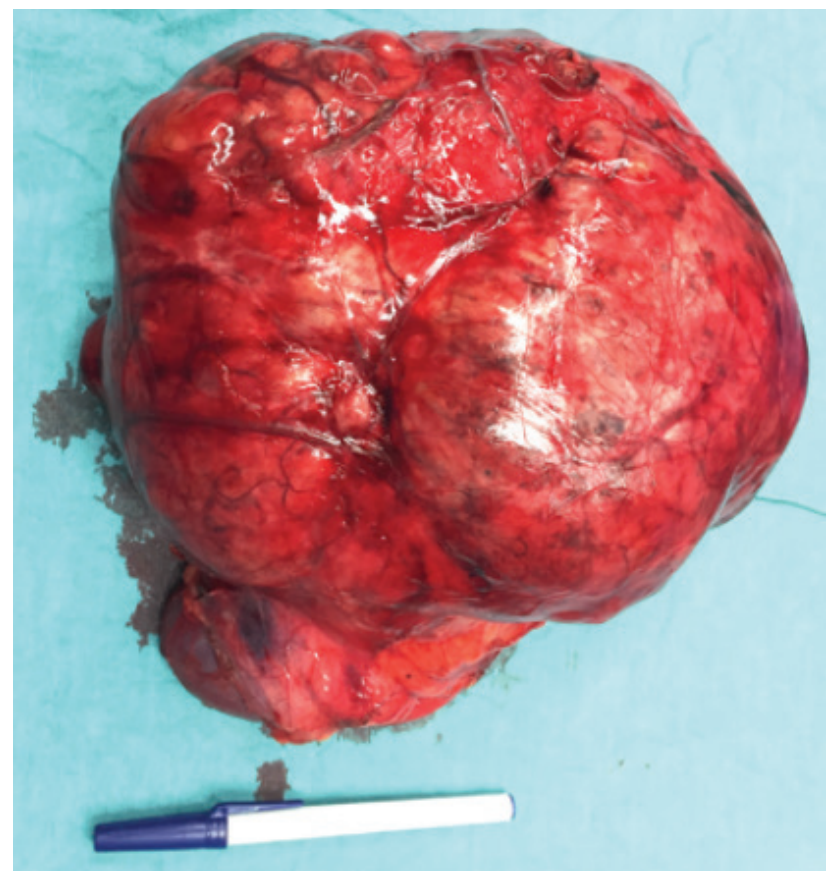

FIGURA 6. Peça operatória. 


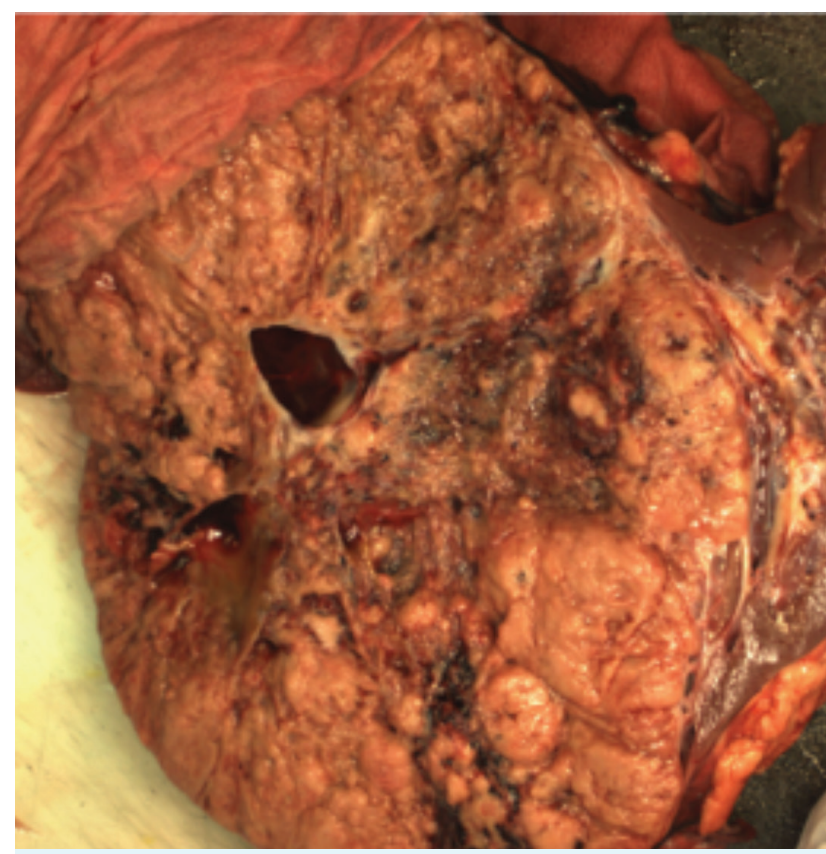

FIGURA 7. Imagem macroscópica de corte da peça operatória.

focos de calcificação, que ocupa o córtex e a medula, sem envolvimento da gordura perirrenal nem invasão da cápsula (Fig.s 7 e 8). Parênquima renal restante sem particularidades. Ureter com $75 \mathrm{~mm}$ de comprimento e $5 \mathrm{~mm}$ de diâmetro, sem particularidades. Não se identificou glândula suprarrenal. O tipo histológico (OMS) foi carcinoma de células renais cromófobo (Fig.s 9 e 10). Sem necrose tumoral, invasão da cápsula, do seio renal, da fáscia Gerota, da veia renal ou pielocalicial. Margens sem tecido neoplásico e invasão linfo-vascular não documentada. Estudos complementares: as células neoplásicas eram difusamente positivas para CK7 (Fig. 11) e muito focalmente para racemasa. Identificaram-se no tumor corpos psamomatosos e áreas com padrão papilar. pTNM: pT2bNx.

À data da redação do artigo o doente encontra-se com dois anos de seguimento e clinicamente bem, sem evidência imagiológica de recidiva local ou à distância da doença. Na Figura 12 mostra-se o aspeto estético aos três meses após a cirurgia.

\section{DISCUSSÃO}

O CCRC é um tumor biologicamente de baixo potencial maligno com taxas de sobrevivência de cinco anos e 10 anos de $78 \%$ a $100 \%$ e de $80 \%$ para $90 \%$, respetivamente. Os parâmetros convencionais de prognóstico que determinam a progressão dos tumores continuam a não estar totalmente caracterizados. Num estudo recente de Amin MB et al, que envolveu 145 casos, foram comparadas as características clínico-patológicas com a evolução clínica. ${ }^{8}$ A idade média dos doentes foi 59 anos

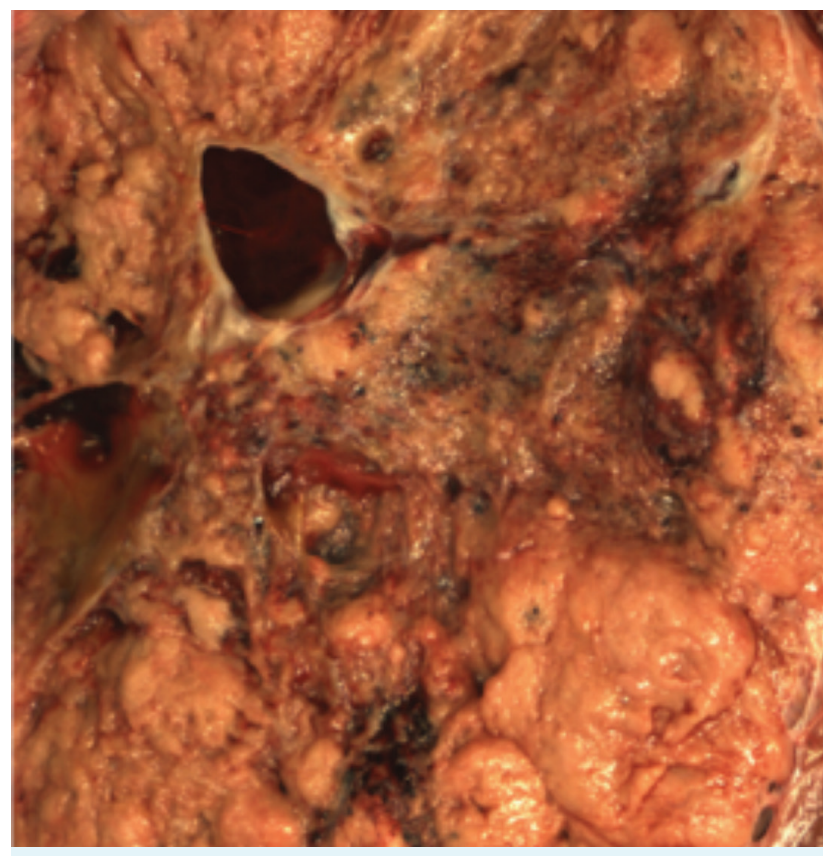

FIGURA 8. Pormenor macroscópico de corte da peça operatória.

(27-82) e o rácio entre homens e mulheres foi de 1,1:1. A maioria dos tumores era bem circunscrita e o tamanho médio era $8 \mathrm{~cm}(1-30 \mathrm{~cm})$. A multifocalidade e bilateralidade estavam presentes em $8 \%$ e 3\% dos casos. Alterações sarcomatoides estavam presentes em 12 dos 145 doentes (8\%). O grau nuclear histológico de Fuhrman foi 1, 2, 3 e 4 em 1\%, 19\%, 74\%, 6\% respetivamente. O estadiamento do tumor primário (pT) foi pT1a, pT1b, pT2, pT3a, pT3b, pT3c, e pT4 em 19\%, 21\%, 28\%, 13\%, 4\%, $1 \%$ e $3 \%$. Dois por cento dos tumores eram pN1 aquando da apresentação e 2,8\% eram tumores M1. A progressão da doença ocorreu em 20 doentes (recorrência local em quatro, metastização em 15 e morte em 10). A análise univariável deste estudo mostrou que o tamanho do tumor ( $p=0,025)$, o estadiamento Pt $(p<0,001)$, a arquitetura alveolar extensa ( $p=0,012)$, o grau nuclear de Fuhrman ( $p<0,001)$, a necrose tumoral microscópica $(p=0,001)$, a invasão vascular $(p=0,020)$ e a transformação sarcomatoide $(p \leq 0,001)$ estavam associados a progressão da doença. Um modelo de regressão multivariada Cox revelou como preditores independentes de CCRC, a transformação sarcomatoide ( $p=0,013$, risco relativo $=4,7$ ), a necrose microscópica ( $p=0,020$, risco relativo $=3,5)$, e o estadiamento $\mathrm{Pt}(p=0,025$, risco relativo de 3,4$)$.

Embora a grande maioria dos CCRC tenha um prognóstico favorável, um subconjunto distinto de doentes tem progressão da doença. $\bigcirc$ estadiamento pT, a necrose tumoral e a transformação sarcomatoide, predizem fenótipos agressivos do CCRC. A presença destas características numa peça de nefrectomia de CCRC, necessita de vigilância apertada dos doentes, e estes podem ser candidatos 


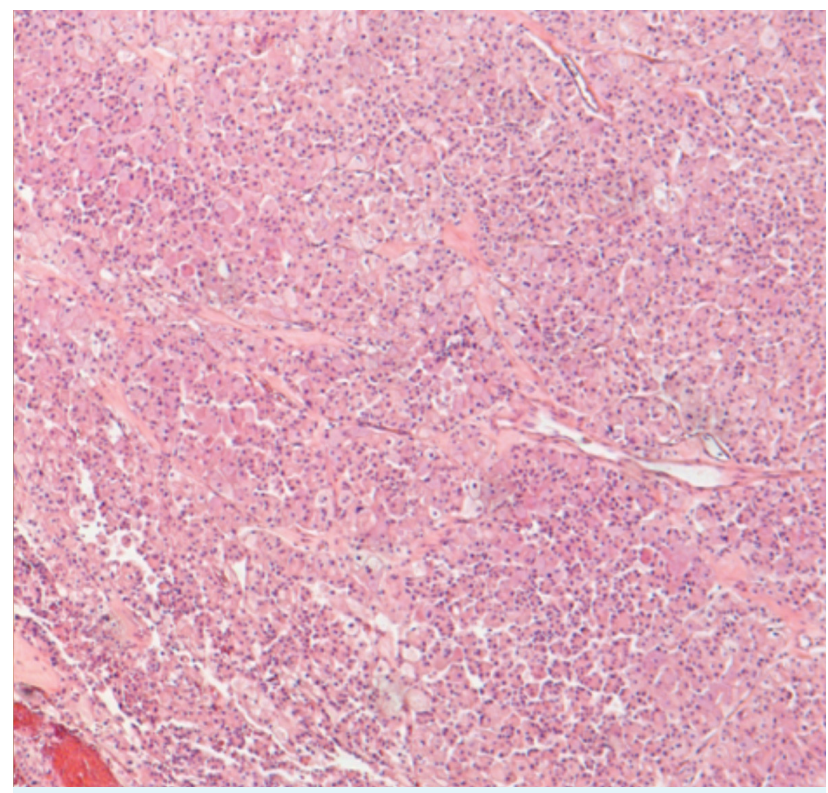

FIGURA 9. HE x 40 - neoplasia epitelial constituída por agregados de células eosinofílicas.

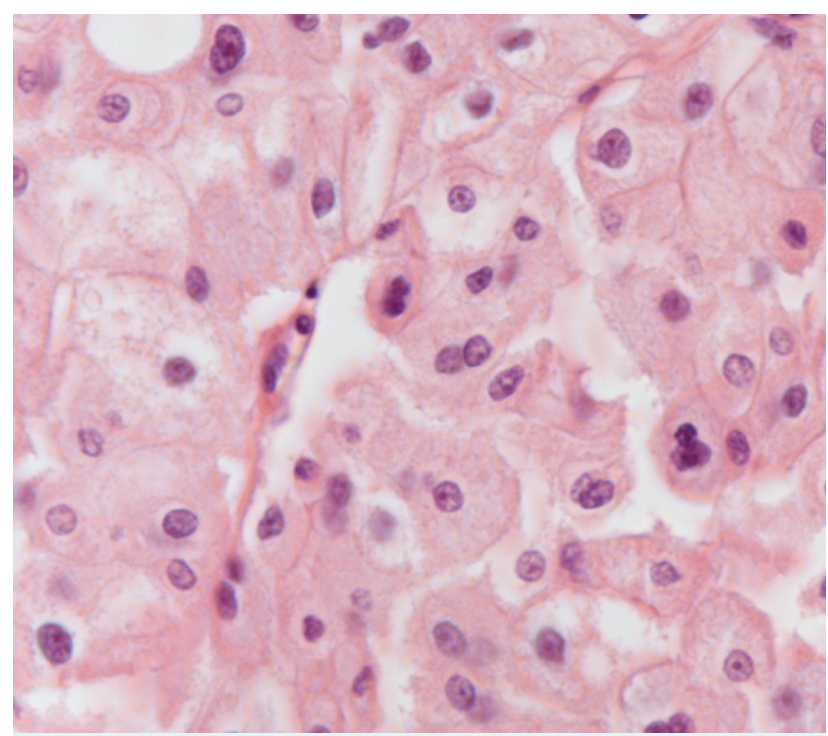

FIGURA 10. HE x 400 - citoplasma granuloso, eosinofílico, com halos perinucleares; ligeiro pleomorfismo nuclear; presença de nucléolos.

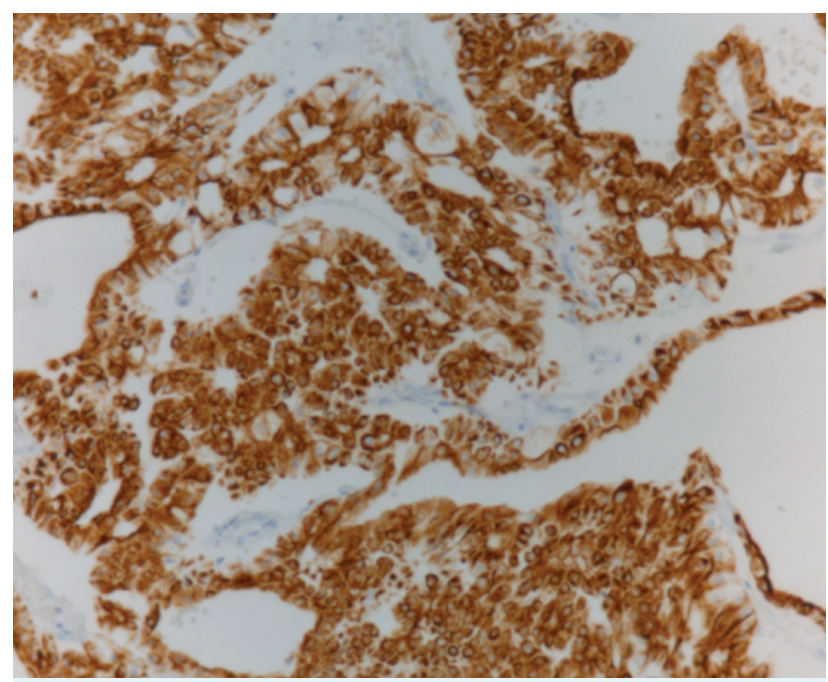

FIGURA 11. CK7 × 100 - expressão positiva de citoqueratina 7.

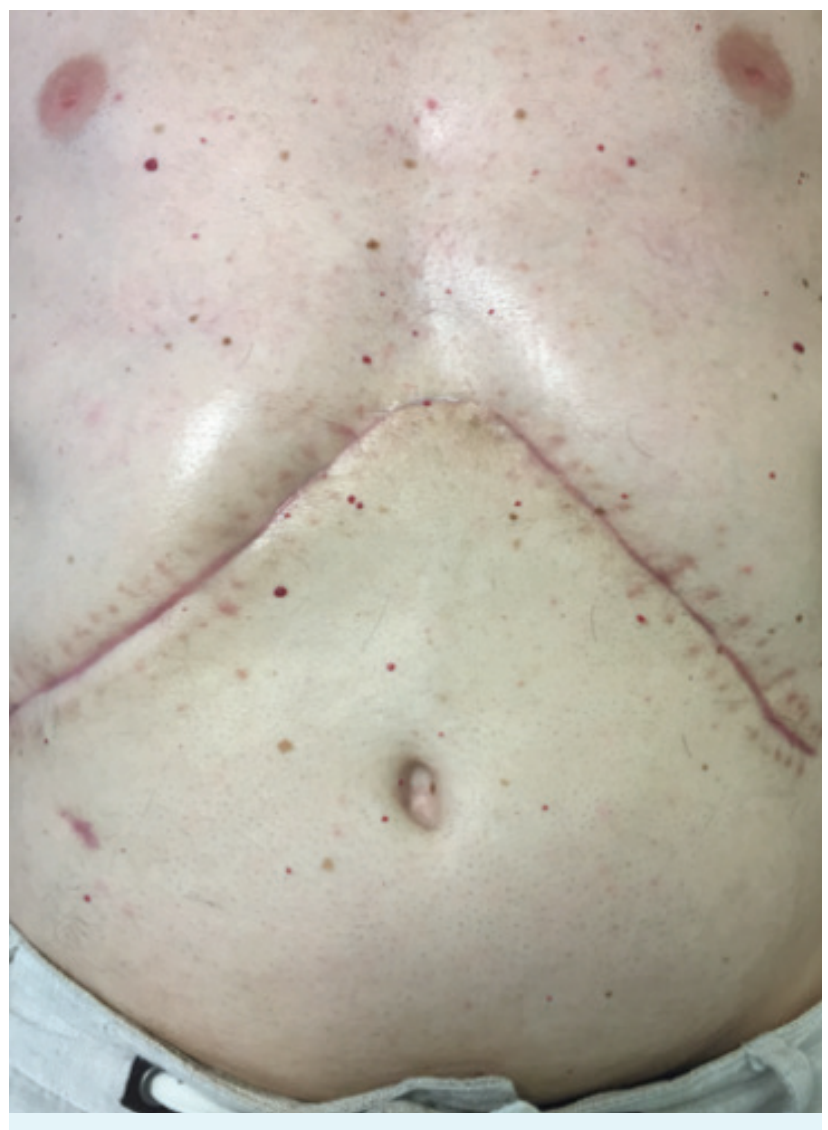

FIGURA 12. Aspeto estético aos 3 meses após a cirurgia.

a terapêuticas adjuvantes se disponíveis. O caso descrito não apresenta nenhum destes critérios de agressividade, pelo que o prognóstico parece ser favorável.

CONFLITOS DE INTERESSE: Os autores declaram não ter qualquer conflito de interesse na realização do presente trabalho.

FONTES DE FINANCIAMENTO: Não houve qualquer fonte de financiamento na realização do presente trabalho.

CONFIDENCIALIDADE DOS DADOS: Os autores declaram ter seguido os protocolos da sua instituição acerca da publicação dos dados de doentes.

PROTEÇÃO DE PESSOAS E ANIMAIS: Os autores declaram que os procedimentos seguidos na elaboração do presente trabalho estão em conformidade com as normas das comissões de investigação clínica e de ética, bem como da declaração de Helsínquia e da Associação Médica Mundial.

CONFLICTS OF INTEREST: The authors declare that they have no conflicts of interest.

FINANCIAL SUPPORT: This work has not received any contribution, grant or scholarship.

CONFIDENTIALITY OF DATA: The authors declare that they have followed the protocols of their work center on the publication of data from patients. 
PROTECTION OF HUMAN AND ANIMAL SUBJECTS: The authors declare that the procedures followed were in accordance with the regulations of the relevant clinical research ethics committee and with those of the Code of Ethics of the World Medical Association (Declaration of Helsinki).

\section{REFERÊNCIAS}

1. Chen DY, Uzzo RG. Evaluation and management of the renal mass. Med Clin North Am. 2011;95:179-89.

2. Lam JS, Shvarts O, Pantuck AJ. Changing concepts in the surgical management of renal cell carcinoma. Eur Urol. 2004;45:692-705.

3. Gershman B, Moreira DM, Boorjian SA. Comprehensive characterization of the perioperative morbidity of cytoreductive nephrectomy. Eur Urol. 2016;69:84-91.

4. Griffin N, Grant LA, Bharwani N, Sohaib SA. Computed tomography in metastatic renal cell carcinoma. Semin. Ultrasound CT MR. 2009;30:359-66.
5. Chiong E, Wood CG, Margulis V. Role of cytoreductive nephrectomy in renal cell carcinoma. Future Oncol. 2009;5:859-69.

6. Capitanio U, Cloutier V, Zini L, Isbarn H, Jeldres C, Shariat SF, et al. A critical assessment of the prognostic value of clear cell, papillary and chromophobe histological subtypes in renal cell carcinoma: a population-based study. BJU Int. 2008;103:1496-500.

7. Suzuki K, Kubo T, Morita T. A giant chromophobe renal cell carcinoma exceeding $10 \mathrm{~kg}$. Int J Urol. 2009;16:976.

8. Amin MB, Pauner GP, Alvarado-Caberero I, Young AN, Stricker $\mathrm{HJ}$, Lyles RH, et al. Chromophobe renal cell carcinoma: histomorphologic characteristics and evaluation of conventional pathologic prognostic parameters in 145 cases. Am J Surg Pathol. 2008;32:1822-34.

9. Caricato M, Valeri S, Ausania F, Caputo D, Rabitti C, Coppola R. Giant abdominal sarcoma. Colorectal Dis. 2005;7:422-3.

10. Renshow AA, Henske EP, Loughlin KR, Shapiro C, Weinberg DS. Aggressive variants of chromophobe renal cell carcinoma. Cancer. 1996;78:1756-61. 